\title{
Prevalence of generalized joint hypermobility in children with anxiety disorders
}

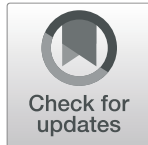

\author{
Vadood Javadi Parvaneh ${ }^{1}$, Shadialsadat Modaress ${ }^{1}$, Ghazal $_{\text {Zahed }}{ }^{2 *}$, Khosro Rahmani $^{1}$ and Reza Shiari ${ }^{1}$
}

\begin{abstract}
Background: Concerning the high prevalence of anxiety disorders and joint hypermobility in children and the lack of related studies in this age group, we aimed to assess the association of hypermobility with anxiety disorders in children.

Methods: In this case-control study, 93 children ages 8-15 years with anxiety disorders referring to the Child and Adolescent Psychiatry Clinic of Mofid Children's Hospital, Tehran, Iran, during 2018, were enrolled. The control group consisted of 100 age and sex-matched children without anxiety disorders. Anxiety was evaluated using the Spence Children Anxiety Scale (SCAS). The diagnosis of generalized joint hypermobility was done based on Beighton and Shiari-Javadi criteria.

Results: Based on Beighton's diagnostic criteria $52.7 \%$ of the children in the case group and $16 \%$ of the children in the control group had generalized joint hypermobility. Moreover, based on Shiari-Javadi criteria, 49.5 and 13\% of the children in the case and control groups had generalized joint hypermobility, respectively. Moreover, the internal correlation between the two criteria was 0.91 showing almost complete compatibility between the two $(P<0.001)$. Age was a risk factor that could predict hypermobility in these children. Other variables such as sex, severity, and type of anxiety disorders, and ADHD, were not predictors of hypermobility syndrome.
\end{abstract}

Conclusion: The prevalence of hypermobility was three times higher in children with anxiety disorders and only age was a predictor for the possibility to suffer from generalized joint hypermobility in these children.

Keywords: Anxiety disorders, Hypermobility, Beighton, Shiari-Javadi, Children

\section{Background}

The term joint hypermobility was first introduced to the medical dictionary in the late nineteenth century to define Marfan and Ehlers-Danlos syndromes [1]. Although joint hypermobility is characteristic of several collagen disorders such as Marfan, Ehlers-Danlos syndromes and osteogenesis imperfecta, generalized hypermobility can also be seen in a relatively high percentage of healthy

\footnotetext{
* Correspondence: ghazal.zahed@gmail.com

${ }^{2}$ Child and Adolescent Psychiatry department, Mofid Children's Hospital, Shahid Beheshti University of Medical Sciences, Shariati Ave, Hosseinieh Ershad, Tehran, Iran

Full list of author information is available at the end of the article
}

individuals [2, 3]. The prevalence of hypermobility ranges from 7 to $38.5 \%$ depending on age, sex, and race [4]. Joint hypermobility-related disorders are on a wide spectrum, ranging from asymptomatic generalized hypermobility to symptomatic hypermobility which includes hypermobility spectrum disorders (HSDs) and hypermobile Ehlers-Danlos syndrome (hEDS). HSDs are relatively common in childhood. All patients with generalized joint hypermobility, which have musculoskeletal complaints or comorbidities related to hypermobility, are diagnosed as having hypermobility spectrum disorders if they do not fulfill hypermobile Ehlers-Danlos

(c) The Author(s). 2020 Open Access This article is licensed under a Creative Commons Attribution 4.0 International License, which permits use, sharing, adaptation, distribution and reproduction in any medium or format, as long as you give appropriate credit to the original author(s) and the source, provide a link to the Creative Commons licence, and indicate if changes were made. The images or other third party material in this article are included in the article's Creative Commons licence, unless indicated otherwise in a credit line to the material. If material is not included in the article's Creative Commons licence and your intended use is not permitted by statutory regulation or exceeds the permitted use, you will need to obtain permission directly from the copyright holder. To view a copy of this licence, visit http://creativecommons.org/licenses/by/4.0/ The Creative Commons Public Domain Dedication waiver (http://creativecommons.org/publicdomain/zero/1.0/) applies to the data made available in this article, unless otherwise stated in a credit line to the data. 
syndrome and other hereditary connective tissue disorders criteria [5-8]. Recent studies show that hypermobility spectrum disorder is not restricted to the motor system or joints and could be associated with comorbidities such as mitral valve prolapse, visceral symptoms, and psychological problems $[9,10]$.

So far, many studies have been done on the psychological manifestations of hypermobility. In a systematic review of 35 studies on the psychological manifestations of joint hypermobility, joint hypermobility syndrome, and Ehlers-Danlos syndrome, of which 21 assessed the association between anxiety disorder and joint hypermobility. Seventeen articles showed a statistically significant association between anxiety disorders and joint hypermobility, while 4 did not find such a relationship. It should be stated that all these 21 studies were done on the adult population and to the best of our knowledge no related study has been so far done on children [11]. In another study comparing the grey matter volume in adults with anxiety disorders and healthy individuals, the researchers found a significant relationship between the size of the amygdala and the hypermobility score in these patients, while no such relationship was reported in non-anxious adults [12]. The amygdala contributes to emotional processing such as anxiety, fear, and sadness. It is highly responsive to emotional and stressful events. Consistently, hypermobility syndrome has been identified as a risk factor predicting anxiety disorders in adults over 60 years [13].

The prevalence of mental disorders in children and adolescents that moderately interferes with their performance has been reported to be around 20\%, among which anxiety disorder is the most prevalent (13\%) [14]. The coexistence of psychological problems and physical illnesses such as neuromuscular diseases deteriorate the patient's condition and lead to an unsuitable therapeutic response to current treatments. This is because most physical illnesses debilitate children which would in turn increase anxiety and its types such as generalized anxiety. Moreover, the parents' concerns would lead to increased tension and anxiety in the family which intensifies anxiety disorder [15].

\section{Methods}

\section{Study design and participants}

In this case-control study, 93 children ages $8-15$ years with anxiety disorders referred to the Child and Adolescent Psychiatry Clinic of Mofid Children's Hospital, Tehran, Iran, during 2018, were enrolled consecutively. The control group consisted of 100 age and sexmatched children who visited in emergency and surgery clinics without any chronic or underlying diseases and without anxiety disorders. Anxiety was evaluated using the Spence Children Anxiety Scale (SCAS). This scale was developed by Spence in 1997 to assess anxiety in 815-year-old children based on the DSM-IV categorization. It has two versions: the child version with 45 items and the parent version with 38 items, evaluating six domains. It is scored on a four-item Likert scale from zero to three. The six subscales of the SCAS are as follows: separation anxiety, social phobia, obsessivecompulsive disorder, panic/agoraphobia, generalized anxiety, and specific phobia [16]. The validity of the scale for the Iranian population has been previously confirmed with a Cronbach's alpha of 0.86 [17]. The criteria for confirming anxiety are as follows: total score of $>40$ in boys and $>50$ in girls aged 8-11 years, and total score of $>33$ in boys and $>40$ in girls aged $12-15$ years. Scores of 0-44 show mild anxiety, 44-88 moderate anxiety, and over 88 depict severe anxiety in children.

We have previously proposed the new specific diagnostic criteria for children (Shiari-Javadi) and compare it with Beighton criteria in most our researches about the hypermobility. In this study, the diagnosis of generalized joint hypermobility was done by a pediatric rheumatologist based on Beighton [18] and Shiari-Javadi criteria [19]. Beighton's scores range from zero to nine and scores higher than six show hypermobility [18, 20], while according to the Shiari-Javadi criteria, scores range from zero to eight, and scores higher than six show hypermobility of the joints. (Table 1).

\section{Statistical analysis}

Data were analyzed using SPSS software, version 16. Mean and standard deviations, as well as frequencies, were calculated as appropriated. Chi-square and t-tests were used to assess the association between variables and between-group differences. ROC curve analysis was done to assess the diagnostic specificity and sensitivity of the Shiari-Javadi criteria compared with Beighton's criteria. Binary logistic regression was used to identify risk factors of hypermobility syndrome in children with an anxiety disorder. We evaluated the association of variants including age, gender, anxiety severity, anxiety type, and ADHD with hypermobility. Other factors such as environmental or genetic factors were not in the aims of the study. The Nagelkerke $R^{2}$ values in logistic regression models for Beighton and Shiari-javadi criterias were 0.23 and 0.24 respectively. $P<0.05$ was considered statistically significant.

\section{Results}

In the case group, 93 children with anxiety disorders were assessed and compared with 100 children without an anxiety disorder. There was no statistically significant difference between both groups concerning age and sex (Table 2). Based on Beighton's diagnostic criteria 52.7\% of the children in the case group and $16 \%$ of the children 
Table 1 Maneuvers and scores of Shiari-Javadi Criteria for generalized joint hypermobility

\begin{tabular}{lll}
\hline Numbers & Maneuvers & score \\
\hline 1 & Passive back hyperextension $>30^{\circ}$ & 1 \\
2 & Bilateral passive lateral neck rotation in which nose crosses & 1 \\
& Imaginary line down the frontal appendage of acromio-clavicular joint \\
3 & Bilateral passive MCPS hyperextension $>90^{\circ}$ \\
4 & Elbows hyperextension $\geq 10^{\circ}$ \\
5 & Vertical shoulders hyperextension so that elbows touch together from behind \\
7 & Passive hips abduction so that the angle between them $>120^{\circ}$ & 1 \\
8 & Passive knees hyperextension $>10^{\circ}$ \\
Total Scores & Thumbs hyperextension so that thumbs touch volar aspect of forearm & 1 \\
\hline
\end{tabular}

in the control group had generalized joint hypermobility. Moreover, based on Shiari-Javadi criteria, 49.5 and 13\% of the children in the case and control groups had generalized joint hypermobility, respectively. A significant difference was found between the rate of generalized joint hypermobility based on the two criteria in the case and control groups (Kapp $=0.834, P<0.001$, Table 2). Moreover, the internal correlation between the two criteria was 0.91 showing almost complete compatibility between the two (95\%CI: 0.88-0.93, $P<0.001$ ). Sensitivity, specificity, positive and negative predictive values, effectiveness, and area under ROC curve were 96.9, 84.6, 92.5, 93.2, 92.7, and $0.907 \%$, respectively.

With respect to the severity of anxiety disorders in the case group, 37 (39.8\%) children had mild anxiety and 56 $(60.2 \%)$ had moderate anxiety. With respect to type, 63 $(67.7 \%)$ children had separation anxiety, 30 (32.3\%) had social phobia, 45 (48.4\%) had obsessive-compulsive disorder, 40 (43\%) had panic/agoraphobia, 68 (73.1\%) had specific anxiety, and 85 (91.4\%) had generalized anxiety. Moreover, in clinical examination, other psychiatric disorders were also diagnosed such as Attention Deficit/ Hyperactivity Disorder (ADHD, $n=30,32.3 \%$ ), mood disorders $(n=9,9.7 \%)$, Stereotypic Movement Disorders $(n=3,3.2 \%)$, school refusal $(n=2,2.2 \%)$, motor tic $(n=$ $2,2.2 \%)$, somatic symptom disorder $(n=1,1.1 \%)$, learning disability $(n=1,1.1 \%)$, and functional constipation $(n=1,1.1 \%)$.

Table 2 Characteristic data and diagnosis of joint hypermobility syndrome in case and control's children

\begin{tabular}{llll}
\hline & Case group $n=93$ & Control group $n=100$ & $P$-value \\
\hline Sex $^{\mathrm{a}}$ Male & $59(63.4)$ & $59(59)$ & 0.55 \\
Age $^{\mathrm{b}}$ Year & $10.3 \pm 2.1$ & $10.6 \pm 2.0$ & 0.14 \\
Hypermobility syndrome & & \\
Beighton $^{\mathrm{a}}$ & $49(52.7)$ & $16(16)$ & $<0.001$ \\
Shiari-Javadi $^{\mathrm{a}}$ & $46(49.5)$ & $13(13)$ & $<0.001$ \\
\hline $\mathrm{a}=\mathrm{n}(\%), \mathrm{b}=$ Mean \pm SD & &
\end{tabular}

We found that based on Beighton's criteria, in children with anxiety disorders, those who were younger had a higher risk of suffering from generalized joint hypermobility (Table 3). As shown in Table 2, other variables such as sex, severity and type of anxiety disorders, and ADHD, were not predictors of generalized joint hypermobility. Repeating the evaluations using the Shiari-Javadi criteria yielded similar results to those of Beighton's criteria (Table 4).

\section{Discussion}

Hypermobility is a tissue-related clinical condition that is usually hereditary and more prevalent in women [21]. In this study, we used two diagnostic criteria for diagnosing hypermobility of the joints. We found that the two criteria were highly compatible with each other. On the basis of the international consensus statement on the Beighton score 2017, Beighton criteria are the standard criteria with acceptable inter-rater reliability in clinical practice [18]. However, it has been proposed for all age groups and it is not specific for children. Furthermore, it has some limitations in pediatric group such as: a) performing the forward bending maneuver in young children is difficult and challenging, b) hypermobility of cervical and total spinal column has been ignored, while this is important in children with hypermobility, c) large joints such as shoulders and hips have not been considered or underscored. For children, one cut-off point, varying from 5 to 7 was used in Beighton score $(5 / 9,6 / 9$, and 7/9). So, we used cut-off point $>6 / 9$ for both Beighton and Shiari-Javadi criteria.

Moreover, we found a significant association between generalized joint hypermobility and anxiety disorders in children, so that this phenotype was three times more prevalent in children with anxiety disorders. This finding is consistent with several previous studies [13, 16, 18-24]. The mentioned studies were all done on the adult population and we found such association in children as well. The most prevalent anxiety 
Table 3 Risk factors of JHS in children with AD based onBeighton criteria

\begin{tabular}{|c|c|c|c|c|c|c|}
\hline & \multirow[t]{2}{*}{$\mathrm{JHS} n=49$} & \multirow{2}{*}{$\begin{array}{l}\text { Non JHS } \\
n=44\end{array}$} & \multirow[t]{2}{*}{ Sig } & \multirow[t]{2}{*}{ OR } & \multicolumn{2}{|l|}{$95 \% \mathrm{Cl}$} \\
\hline & & & & & Lower & Upper \\
\hline Sex ${ }^{a}$ male & $28(57.1)$ & $31(70.5)$ & 0.07 & 0.39 & 0.14 & 1.09 \\
\hline Age $^{\mathrm{b}}$ year & $9.69 \pm 1.93$ & $10.89 \pm 2.13$ & 0.02 & 0.75 & 0.59 & 0.95 \\
\hline \multicolumn{7}{|l|}{ AD Severity } \\
\hline Mild $^{a}$ & $22(44.9)$ & $15(34.1)$ & 0.06 & 0.27 & 0.06 & 1.08 \\
\hline Moderate $^{a}$ & $27(55.1)$ & $29(65.9)$ & & & & \\
\hline \multicolumn{7}{|l|}{ AD Type } \\
\hline Separation anxiety & $34(69.4)$ & $29(65.9)$ & 0.25 & 2.20 & 0.57 & 8.43 \\
\hline Social phobia & $17(34.7)$ & $13(29.5)$ & 0.22 & 2.05 & 0.65 & 6.50 \\
\hline OCD & $22(44.9)$ & $23(52.3)$ & 0.92 & 0.95 & 0.36 & 2.48 \\
\hline Panic/agoraphobia & $19(38.8)$ & $21(47.7)$ & 0.77 & 0.82 & 0.23 & 2.95 \\
\hline Specific phobia & $36(73.5)$ & $32(72.7)$ & 0.70 & 0.79 & 0.25 & 2.55 \\
\hline Generalized anxiety & $44(89.8)$ & $41(93.2)$ & 0.88 & 1.14 & 0.18 & 7.12 \\
\hline ADHD & $12(24.5)$ & $18(40.9)$ & 0.05 & 0.36 & 0.12 & 1.03 \\
\hline
\end{tabular}

$\mathrm{a}=\mathrm{n}(\%), \mathrm{b}=$ Mean \pm SD. Abbreviations: JHS Joint Hypermobility Syndrome, AD Anxiety Disorders, OCD Obsessive-Compulsive Disorder

disorders were generalized anxiety (61.4\%), specific phobia (73.1\%), and separation anxiety (67.7\%), respectively. Anxiety is associated with pain-related fear in hypermobile kids. In profoundly anxious hypermobile youths, tension rather than pain gives off an impression of being related to limitations in social and physical working. There might be a common pathway for hypermobility and anxiety. Moreover, in certain inquires about the seriousness of joint hypermobility and anxiety even showed up positively related [25].

We found that more than half the children with anxiety disorders along with hypermobility were boys, which is inconsistent with other studies [26, 27]. This is while based on regression analysis in our study sex was not a predicting factor for hypermobility in children with anxiety disorders. Age evaluations in children with anxiety disorders showed that the mean age in children with generalized joint hypermobility was significantly lower than those without hypermobility $(9.69$ vs 10.89 years based on Beighton's criteria and 9.55 vs 10.95 based on Shiari-Javadi's criteria). Age could significantly predict hypermobility in children with anxiety disorders in our study (OR $=0.75$ CI 95\% $=0.59-0.95$ based on Beighton's criteria and $\mathrm{OR}=0.72 \mathrm{CI} 95 \%=0.56-0.9$ based on Shiari-Javadi's criteria), which is consistent with another study [28].

The severity of anxiety disorders was moderate in our sample $(60.2 \%)$ and this variable could not significantly

Table 4 Risk factors of JHS in children with AD based on Shiari-Javadi criteria

\begin{tabular}{|c|c|c|c|c|c|c|}
\hline & \multirow{2}{*}{$\begin{array}{l}J H S n= \\
46\end{array}$} & \multirow{2}{*}{$\begin{array}{l}\text { Non JHS } \\
n=47\end{array}$} & \multirow[t]{2}{*}{ Sig } & \multirow[t]{2}{*}{ OR } & \multicolumn{2}{|c|}{$95 \% \mathrm{Cl}$} \\
\hline & & & & & Lower & Upper \\
\hline Sex ${ }^{a}$ male & $26(56.5)$ & $33(70.2)$ & 0.06 & 0.38 & 0.13 & 1.04 \\
\hline Age $^{\mathrm{b}}$ year & $9.55 \pm 1.92$ & $10.95 \pm 2.06$ & 0.01 & 0.72 & 0.56 & 0.92 \\
\hline \multicolumn{7}{|l|}{ AD Severity } \\
\hline Mild $^{a}$ & $20(43.5)$ & $17(36.2)$ & 0.06 & 0.26 & 0.06 & 1.10 \\
\hline Moderate $^{a}$ & $26(56.5)$ & $30(63.8)$ & & & & \\
\hline \multicolumn{7}{|l|}{ AD Type } \\
\hline Separation anxiety & 34 (73.9) & $29(61.7)$ & 0.09 & 3.24 & 0.82 & 12.82 \\
\hline Social phobia & $16(34.8)$ & $14(29.8)$ & 0.32 & 1.77 & 0.57 & 5.53 \\
\hline OCD & $21(45.7)$ & $24(51.1)$ & 0.97 & 0.98 & 0.37 & 2.57 \\
\hline Panic/agrophobia & $18(39.1)$ & $22(46.8)$ & 0.70 & 0.78 & 0.21 & 2.82 \\
\hline Specific phobia & $35(76.1)$ & $33(70.2)$ & 0.86 & 0.90 & 0.27 & 2.94 \\
\hline Generalized anxiety & $41(89.1)$ & $44(93.6)$ & 0.73 & 1.38 & 0.21 & 8.76 \\
\hline ADHD & $13(28.3)$ & $17(36.2)$ & 0.29 & 0.57 & 0.20 & 1.60 \\
\hline
\end{tabular}


predict hypermobility in children with anxiety disorders. Type of anxiety disorder has a similar condition with respect to predicting hypermobility. This is while Bulbena and colleagues found that the prevalence of panic/agoraphobia, social phobia, and simple phobia was higher in people with hypermobility [22]. This inconsistency could be attributed to the different protocols of the study; in the mentioned study the case group comprised 29 people with hypermobility and the control group comprised 108 people without it, while in our study the case group consisted of children with anxiety disorders and the control group comprised children without anxiety disorders.

We also found that comorbidity of ADHD with an anxiety disorder was not a significant predictor of hypermobility, which is inconsistent with two other studies showing a higher prevalence of hypermobility in children with $\operatorname{ADHD}(15,29)$. In the mentioned studies ADHD was considered as the main disorder whose relationship with hypermobility was assessed while we considered ADHD alongside anxiety disorders.

\section{Conclusion}

The prevalence of hypermobility was higher in children with anxiety disorders. Age was a risk factor that could predict hypermobility in these children. Other variables such as sex, severity, and type of anxiety disorders, and ADHD, were not predictors of generalized joint hypermobility.

Although generalized joint hypermobility is a physiologic musculoskeletal variant in children without complaints, this study in children and similar findings in adults proposed that in approach to anxiety or hypermobility, the clinician should be alert about the association of these problems. In a child with an anxiety disorder, the practitioner should focus on somatic complaints in history taking and on generalized joint hypermobility in the physical examination. This matter may be a clue for the diagnosis of joint hypermobility syndrome. This finding (due to having pain) can be a reason for induction or intensifying anxiety in a child. This association alertness may help the physician in disease management, so that with intervention to manage each of these situations the result may affect others.

\section{Abbreviations}

SCAS: Spence children anxiety scale; ROC curve: Receiver operating characteristic curve; ADHD: Attention Deficit/Hyperactivity Disorder; OR: Odd's ratio; Cl: Confidence interval

\section{Acknowledgements}

We would like to offer our special thanks to the Mofid Clinical Research Development Center for providing support, and methodology and statistical advising.

\section{Authors' contributions}

VJP study concepts; study design; definition of intellectual content; literature research; clinical studies; supervision of statistical analysis; manuscript writing. SSM, KR and RS acquisition of medical records and clinical data; literature research. GZ guarantor of integrity of the entire study; study concepts; manuscript editing. All authors read and approved the final manuscript.

\section{Funding}

This research did not receive any specific grant from funding agencies in the public, commercial, or not-for-profit sectors.

\section{Availability of data and materials}

If requested (please contact vadoodj@gmail.com).

\section{Ethics approval and consent to participate}

The study protocol was approved by the Ethics Committee of Shahid Beheshti University of Medical Sciences and registered as

IR.SBMU.MSP.REC.1397.813. The protocol was initially explained to all patients visiting the Psychiatric Clinic of Mofid Children's Hospital and after obtaining a written informed consent from the child and his/her parent/guardian they were enrolled in the study. No extra costs were imposed on the parents besides having the advantage of a free visit by the pediatric rheumatologist and psychiatric. All patients' data were regarded as confidential.

\section{Consent for publication}

We confirm that the written informed consent form has been provided by the parents to have the case details published.

\section{Competing interests}

None.

\section{Author details}

'Department of pediatric rheumatology, Mofid Children's Hospital, Shahid Beheshti University of Medical Sciences, Tehran, Iran. ${ }^{2}$ Child and Adolescent Psychiatry department, Mofid Children's Hospital, Shahid Beheshti University of Medical Sciences, Shariati Ave, Hosseinieh Ershad, Tehran, Iran.

Received: 24 January 2020 Accepted: 28 May 2020

Published online: 02 June 2020

\section{References}

1. Decoster LC, Valias JE, Lindsay RH, et al. Prevalance and features of joint hypermobility among adolescent athletes. ArchPed Adel Med. 1997;151(10): 989-92.

2. Carter C, Wilkinson J. Persitentjoing laxity and congenital dislocation of hip. J Bone Joint Surg. 1994;46:40-51.

3. AK EL-C, Mahamoud A, Mahgoub EH. Hypermobility among egyptian children: prevalence and features. J Rheumatol. 1998;25(5):3-5.

4. Callerweart B, Malfait F, Leoys B, de Paepe A. Ehler-Danlose syndromes and Marfan syndrome. Best Pract Res Clin Rheumatol. 2008;22(1):165.

5. Castori M, Hakim A. Contemporary approach to joint hypermobility and related disorders. Curr Opin Pediatr. 2017;29(6):640-9.

6. Russek LN, Stott P, Simmonds J. Recognizing and effectively managing hypermobility-related conditions. Phys Ther. 2019;99(9):1189-200.

7. Malfait F, Francomano C, Byers P, Belmont J, Berglund B, Black J, et al. The 2017 international classification of the Ehlers-Danlos syndromes. Am J Med Genetc C Semin Med Genet. 2017;175(1):8-26.

8. Castori M, Tinkle B, Levy H, Grahame R, Malfait F, Hakim A. A framework for the classification of joint hypermobility and related conditions. Am J Med Genetc C Semin Med Genet. 2017;175(1):148-57.

9. Pournasiri Z, Madani A, Zandi H, Salehpour S, Gorji FA, Ahmadzahe A. Relationship of generalized joint hypermobility with vesicoureteral reflux and urinary tract infection. Iran J Kidney Dis. 2014;8(3):18.

10. Sinibaldi L, Ursini G, Castori M. Psychopathological manifestations of joint hypermobility and joint hypermobility syndrome/ Ehlers-Danlos syndrome, hypermobility type: the link between connective tissue and psychological distress revised. Am J Med Genet C Semin Med Genet 2015;169C(1):97-106.

11. Tung JS, Eccles JA, Harrison NA, Critchley HD. Brain structure and joint hypermobility: relevance to clinical anxiety disorder. J Natl Stud Assoc Med Res. 2018;1(1):33. 
12. Bulbena-Cabré A, Rojo C, Pailhez G, BuronMaso E, Martín-Lopez LM, Bulbena A. Joint hypermobility is also associated with anxiety disorders in the elderly population. Int J Geriatr Psychiatry. 2018;33(1):e113-9.

13. Leonte KG, Puliafico A, Na P, Rynn MA. Pharmacotherapy for anxiety disorders in children and adolescents. Waltham, MA. (Accessed on March 21, 2018: UpToDate; 2018.

14. Pitcher DA, Grahame RO. Mitral valve prolapse and joint hypermobility: evidence for a systemic connective tissue abnormality? Ann Rheum Dis. 1982;41(4):352-4.

15. Spence SH. Structure of anxiety symptoms among children: A confirmatory factor-analytic study. J Abnorm Psychol. 1997;106(2):280-97.

16. Zarghami F, HeidariNasab L, Shaeiri MR, Shahrivar Z. A study in the impact of coping-cat-based cognitive-behavior therapy (CBT) on reduced anxiety in the children aged 8 to 10 with anxiety disorder. Clin Psychol Res. 2015;19(5): 183-202.

17. Beighton P, Solomon L, Soskolne CL. Articular mobility in an African population. Ann Rheum Dis. 1973;32:413-8.

18. Juul-Kristensen B, Schmedling K, Rombaut L, Lund H, Engelbert RHH.2017. Measurement properties of clinical assessment methods for classifying generalized joint hypermobility-A systematic review. Am J Med Genet C Semin Med Genet 175C:116-147.

19. Javadi V, Shiari R. Proposed modifications to Beighton criteria for the diagnosis of joint hypermobility in children. Indian J Rheumatol. 2016;: $: 97-100$

20. Hakim AJ, Malfait F, De Paepe A, Sahota A. The heritable disorders of connective tissue: epidemiology, nosology and clinical features. In: Hakim AJ, Keer R, Grahame R, editors. Hypermobility, fibromyalgia and chronic pain. Edinburgh: Churchill Livingstone/Elsevier; 2010. p. 3-17.

21. Bulbena A, Gago J, Pailhez G, Sperry L, Fullana MA, Vilarroya O. Joint hypermobility syndrome is a risk factor trait for anxiety disorders: a 15-year follow-up cohort study. Gen Hosp Psychiatry. 2011;33(4):363-70.

22. Ercolani M, Galvani M, Franchini C, Baracchini F, Chattat R. Benign joint hypermobility syndrome: psychological features and psychopathological symptoms in a sample pain-free at evaluation. Percept AfotoiSkzlls. 2008; 107:236-56.

23. Murray B, Yashar BM, Uhlmann WR, Clauw DJ, Petty EM. Ehlers-Danlos syndrome, hypermobility type: A characterization of the patients' lived experience. Am J Med Genet 2013; Part A 161A:2981-2988.

24. Scheper MC, de Vries JE, Verbunt J, Engelbert RH. Chronic pain in hypermobility syndrome and Ehlers-Danlos syndrome (hypermobility type): it is a challenge. J Pain Res. 2015;8:-591.

25. Sanches SB, Osório FL, Louzada-Junior P, Moraes D, Crippa JA, Martín-Santos R. Association between joint hypermobility and anxiety in Brazilian university students: gender-related differences. J Psychosom Res. 2014;77(6):558-61.

26. Baeza-Velasco C, Bourdon C, Montalescot L, de Cazotte C, Pailhez G, Bulbena A, et al. Low-and high-anxious hypermobile Ehlers-Danlos syndrome patients: comparison of psychosocial and health variables. Rheumatol Int. 2018;38(5):871-8.

27. Morlino S, Dordoni C, Sperduti I, Venturini M, Celletti C, Camerota F, et al. Refining patterns of joint hypermobility, habitus, and orthopedic traits in joint hypermobility syndrome and Ehlers-Danlos syndrome, hypermobility type. Am J Med Genet A. 2017 Apr 1;173(4):914-29.

28. Doğan ŞK, Taner Y, Evcik D. Benign joint hypermobility syndrome in patients with attention deficit/hyperactivity disorders. Arch Rheumatol. 2011;26(3):187-92.

\section{Publisher's Note}

Springer Nature remains neutral with regard to jurisdictional claims in published maps and institutional affiliations.

\section{Ready to submit your research? Choose BMC and benefit from:}

- fast, convenient online submission

- thorough peer review by experienced researchers in your field

- rapid publication on acceptance

- support for research data, including large and complex data types

- gold Open Access which fosters wider collaboration and increased citations

- maximum visibility for your research: over $100 \mathrm{M}$ website views per year

At BMC, research is always in progress.

Learn more biomedcentral.com/submissions 